\title{
EFFECT OF CHROMIUM POWDER MIXED DIELECTRIC ON PERFORMANCE CHARACTERISTIC OF AISI D2 DIE STEEL USING EDM
}

\author{
Abhishek Abrol ${ }^{1}$, Sunil Sharma ${ }^{2}$ \\ ${ }^{l}$ Assistant Professor, School of Mechanical Engineering, Lovely Professional University, Punjab, India \\ ${ }^{2}$ Assistant Professor, School of Mechanical Engineering, Lovely Professional University, Punjab, India
}

\begin{abstract}
In this paper, the effect of chromium powder mixed dielectric fluid on machining characteristics of AISI D2 die steel has been studied. Peak current, pulse on time, pulse off time, concentration of powder are the process parameters. The process performance is measured in terms of material removal rate (MRR), tool wear rate (TWR) and surface roughness (SR). The research outcome will identify the important process parameters that maximize MRR, minimize TWR and SR. The design of experiment has been undertaken using Taguchi method. ANOVA analysis has been used to investigate the percentage contribution of each process parameter for optimizing the performance. The study indicates that all the selected parameters except pulse off time have a significant effect on MRR. Current is found to be the most significant factor for MRR and TWR. With increase in current, TWR increases. Also, surface roughness increases with increase in pulse off time.
\end{abstract}

Keywords: PMEDM, Material removal rate, Tool wear rate, Surface roughness, Taguchi method

\section{INTRODUCTION}

Electric discharge machining (EDM) is one of the most widely used advanced machining methods for the manufacturing of press tools, die castings and various dies. This process can only machine an electrically conductive material, having any hardness, shape or strength. Being a contactless method, this process can be used to machine weak materials and highly delicate sections. However, lower surface finish values and low machining efficiency limit its further applications. Powder Mixed Electrical Discharge Machining (PMEDM) is a newer material removal process applied to improve the machining efficiency and surface finish using powder mixed dielectric fluid. Researchers have explained the working principle of powder mixed electrical discharge machining process. In this process, a suitable material in the powder form is mixed in the dielectric fluid of EDM. The voltage is applied to both the electrodes. An electric field is generated in the spark gap. The spark gap is filled up with powdered particles and the gap distance setup between tool and the workpiece increases. [24]. The set up is immersed under a dielectric fluid. The electric field energizes the powder particles and they move in a zigzag manner. They arrange to form chains at different places during sparking, which bridge the gap between the electrode and workpiece. Thus, the gap voltage and insulating strength of the dielectric fluid decreases. Short circuit occurs easily and the series of discharge starts under the electrode. With an increase in frequency of discharging, the quicker sparking within the discharge takes place which causes erosion at a higher rate on the workpiece surface.
The added powder particles modify the plasma channel. The plasma channel becomes more enlarge and wide. There is decrease in dielectric density; hence, sparking is uniformly distributed. Thus, due to even distribution of the discharge uniform erosion occurs on the workpiece. As a result, the surface finish is improved.

\section{LITERATURE REVIEW}

It can be easily observed from the available literature that considerable efforts have been directed to improve the material removal rate and the surface quality by suspending powder particles in the dielectric of EDM. Erden and Bilgin [22], 1980 conducted the first study on PMEDM. It has been reported that with an increase in the concentration of suspended powder particles (copper, aluminum, iron, and carbon), the machining rate increases for a mild steel workpiece. They reported that poor machining takes place due to excessive powder concentration. Improvement in material removal rate (MRR) and surface finish (SF) with usage of powder in dielectric has also been reported. Jeswani [1], 1981 investigated the effect of the finely powdered graphite into kerosene oil on the machining of tool steels. He reported that due to an increase in the interspace of powdered particles, electric discharge initiation improved and the breakdown voltage reduced. The machining process stability improved, which caused around $60 \%$ increase in the material removal rate and $28 \%$ reduction in wear ratio. Mohri, Saito and Higash [23], 1991 reported the effect of silicon powder addition into dielectric fluid on the surface finish of $\mathrm{H}-13$ die steel. The fine and corrosion-resistant surfaces having surface finish $(\sim 2 \mu \mathrm{m})$ is achieved at controlled machining conditions (even 
distribution of powder into dielectric, short discharge time, workpiece composition, etc.). Yan et al. [3], 2000 studied the effect of $\mathrm{Si}$ and $\mathrm{Al}$ powder added in Kerosene for the micro-slit machining of Titanium alloy using EDM. Addition of silicon carbide yielded better material removal depth as compared to aluminum powder.

Lee et al. [25], 2001 investigated the characteristics of different powders like aluminum, chromium, copper, silicon carbide with copper electrode. They found that the concentration, size, density, electrical resistivity and thermal conductivity of powders significantly affected the machining performance. For a fixed concentration, the smallest particle size produced highest MRR and lowest tool wear rate (TWR) and that copper powder showed negligible effect on EDM due to its higher density.

Zhao et al. [7], 2002 used aluminum powder for the research on PMEDM in rough machining with copper as electrode. They performed experimental research on the machining efficiency and surface roughness (SR) of PMEDM in rough machining which resulted in improving machining efficiency and SR by selecting proper discharge parameters. Simao [26], 2003 investigated surface modification of AISI $\mathrm{H}-13$ steel with WC/Co electrode material. Using Taguchi method, he identified the effect of various input factors (open circuit voltage, peak current, pulse on time, electrode polarity and capacitance) on output responses (electrode wear rate, workpiece surface hardness, etc.).

Pecas et al. [8], 2003 studied the influence of Si powder mixed Castrol SE Fluid 180 on AISI H-13 steel using conventional EDM. Kansal et al. [11], 2005 studied parametric optimization of PMEDM by response surface methodology. Silicon Powder into kerosene oil has been used as dielectric with copper as electrode to find the effects on EN 31 tool steel.

Kansal et al. [13], 2007 also investigated the effect of silicon powder mixed EDM on machining rate of AISI D2 die steel with copper as electrode. Peak current and concentration of silicon powder being the most influential parameters for causing material removal. Shitij Sood [15], 2008 investigated the effect of power mixed dielectric on MRR, TWR and surface properties of EN31 die steel in EDM. Graphite and copper suspended powders have been mixed into the dielectric kerosene oil. Experiments have been designed using Taguchi method for has been used to investigate the effect of selected process parameters on response factors like MRR, TWR and SR.

Singh et al. [27], 2010 investigated the influence of electrical parameters in powder mixed electric discharge machining of hastelloy. Peak current, gap voltage, pulse on time and duty cycle has been taken as machining parameters. Material removal rate, tool wear rate, \% wear ratio and surface roughness have been taken as response parameters to measure process performance. Increase in current leads to increase in MRR and SR. TWR increases and reaches a maxima and then starts decreasing.
Singh et al. [6], 2010 investigated the improvement of material properties and parametric optimization of MRR, TWR and surface roughness using aluminum and graphite powder mixed kerosene oil and transformer oil in EDM process. The effect of different input parameters (current, workpiece material, electrode material, dielectric medium, pulse on time, pulse off time and powder and their interactions) on the MRR, TWR, micro-hardness and surface roughness of $\mathrm{HCHCr}, \mathrm{EN}-31$ and $\mathrm{H}-11$ die steel using copper, tungsten-copper electrodes has been analyzed. Ojha et al. [20], 2011 investigated the effect of nickel micropowder suspended dielectric on EDM performance measures of EN-19 steel using Response Surface Methodology (RSM). Peak Current, pulse on time, diameter of electrode and concentration of micro-nickel powder added into the dielectric fluid of EDM have been chosen as process parameters to study the PMEDM performance in terms of MRR, TWR and SR. Maximum MRR is obtained at high current. MRR is found to increase with duty cycle and powder concentration. Powder concentration has much significant effect on MRR. Also, current is important parameter affecting the TWR.

\subsection{Literature Gap}

Over the last two decades, work has been done in the field of PMEDM (Powder Mixed Electric Discharge Machining) on the process performance such as MRR, TWR and SR. However, the data is insufficient about variability of process parameter for a particular powder to a known workpiece and electrode. Also, the critical size of powder and its variation with other process parameters is yet to be determined. This can be accomplished by conclusive experimental work. By taking different powders, varying workpiece and electrode material in experimental work, researchers can find out optimum value of various process parameters. In the past, various researchers have used powders like silicon, silicon carbide, aluminum mixed in dielectric for the machining of workpiece material. Nickel, chromium, graphite, copper etc., are the powdered materials which can be mixed in dielectric. Tool steel and alloy steel has been commonly used as workpiece by various researchers. These materials have been selected due to their hardness, resistance to abrasion, their ability to hold a cutting edge and their resistance to deformation at elevated temperatures (redhardness). Materials like water hardened die steel, molybdenum high speed tool steel have not been tried yet as work material. Copper electrode has been most frequently used as electrode.

\section{EXPERIMENTAL SETUP}

AISI D2 die steel is selected as a workpiece specimen. The chemical composition of AISI D2 die steel has been shown in Table 1. Powdered chromium mixed kerosene oil as dielectric has been used to machine AISI D2 die steel. Powdered chromium particle size is in the range of order 45$55 \mu \mathrm{m}$. The chemical composition has been shown in Table 2. The properties of chromium powder have been shown in Table 3. Copper electrode with diameter $14 \mathrm{~mm}$ is chosen to machine AISI D2 die steel. Kerosene oil has been used as a dielectric and the properties have been shown in Table 4. 
Table -1: Chemical composition of AISI D2 die steel

\begin{tabular}{|l|l|}
\hline Element & $\%$ \\
\hline $\mathrm{C}$ & 1.43 \\
\hline $\mathrm{Si}$ & 0.297 \\
\hline $\mathrm{Mn}$ & 0.492 \\
\hline $\mathrm{P}$ & 0.0198 \\
\hline $\mathrm{S}$ & 0.0166 \\
\hline $\mathrm{Cr}$ & 11.3 \\
\hline $\mathrm{Mo}$ & 0.789 \\
\hline $\mathrm{Co}$ & 0.82 \\
\hline $\mathrm{W}$ & 0.512 \\
\hline $\mathrm{V}$ & 0.653 \\
\hline
\end{tabular}

Table -2: Chemical composition of AISI D2 die steel

\begin{tabular}{|l|l|}
\hline Particle Size & $45-55 \mu \mathrm{m}$ \\
\hline Particle Shape & Spherical \\
\hline $\mathrm{Cr}(\%)$ & 99 \\
\hline $\mathrm{C}(\%)$ & 0.01 \\
\hline $\mathrm{S}(\%)$ & 0.015 \\
\hline $\mathrm{P}(\%)$ & 0.015 \\
\hline $\mathrm{Si}(\%)$ & 0.09 \\
\hline $\mathrm{Al}(\%)$ & 0.08 \\
\hline $\mathrm{Fe}(\%)$ & 0.01 \\
\hline
\end{tabular}

Table -3: Properties of chromium powder

\begin{tabular}{|l|l|}
\hline Density $\left(\mathrm{g} / \mathrm{cm}^{3}\right)$ & 7.16 \\
\hline Melting Point $\left({ }^{\circ} \mathrm{C}\right)$ & 1875 \\
\hline Specific Heat $(\mathrm{cal} / \mathrm{g} / \mathrm{deg})$ & 0.11 \\
\hline Electrical conductivity & $7.9 \times 10^{6}$ \\
\hline Electrical resistivity $(\mu \Omega \mathrm{cm})$ & 0.026 \\
\hline $\begin{array}{l}\text { Thermal conductivity } \\
(\mathrm{w} / \mathrm{cm} / \mathrm{K})\end{array}$ & 0.67 \\
\hline
\end{tabular}

Table -4: Properties of Kerosene Oil

\begin{tabular}{|c|c|}
\hline Dielectric constant, K & 1.8 \\
\hline $\begin{array}{l}\text { Electrical conductivity, } \\
\mathrm{s} / \mathrm{m}\end{array}$ & $1.6 \times 10$ \\
\hline Mobility, $\mathrm{m}^{2} / \mathrm{Vs}$ & $2.2 \times 10^{-8}$ \\
\hline Electric field, MV/m & 16.6 \\
\hline $\begin{array}{lll}\begin{array}{l}\text { Dynamic } \\
\text { Pas }\end{array} & \text { viscosity, } & m \\
\end{array}$ & 0.92 \\
\hline Mass density, $\mathrm{kg} / \mathrm{m}^{3}$ & 728 \\
\hline
\end{tabular}

\subsection{Experimental Settings}

The experiments are conducted on T-3822 EDM machine manufactured by Electronica Machine Tools, India. The dielectric fluid i.e. kerosene oil is put in the machining tank. A stirring system is also used to prevent settling down of the powdered particles. A small dielectric circulation pump is installed to ensure proper circulation of the powder-mixed dielectric fluid in the discharge gap by means of $25 \mathrm{~mm}$ diameter plastic pipe with $3 \mathrm{~mm}$ diameter holes in it (power rating is $1.5 \mathrm{~W}$, flow rate is $500 \mathrm{l} / \mathrm{h}$, and the diameter of the ejector nozzle is $4 \mathrm{~mm}$ ). The distance between the powdermixed dielectric suction point and the nozzle outlet is made as short as possible to ensure the complete suspension of powder in the discharge gap. The main dielectric sump has disconnected from dielectric tank by valve arrangements.

The machining parameters have been kept fixed throughout the experiment. The open gap output voltage is $135 \mathrm{~V}$. The polarity is positive (straight) and machining time is 15 minutes. The dielectric used is kerosene oil and tool electrode is copper having diameter of $14 \mathrm{~mm}$. Though the process parameters governing the PMEDM process are numerous, the following four process parameters have been selected for this study.

1) Discharge or Peak current, A

2) Pulse on time, $B$

3) Pulse off time, $C$

4) Concentration of powder particle, $D$

Each of the above four parameters has three levels. The selected process parameters and their levels are as shown in Table 5. Other process parameters have been kept constant.

\subsection{Design of Experiment}

To investigate the effect of the process parameters on PMEDM performance, various approaches can be followed. The most commonly used approach is highly fractional factorial experimental design (also known as Taguchi method). This method reduces the number of experiments to be performed which reduces the time consumed and the overall cost incurred [24]. This method uses a special design of orthogonal array to study the entire process parameter space with lesser number of experiments. A simple, efficient, and systematic Taguchi method is used for the design of the experiment. The Taguchi method uses signalto-noise $(\mathrm{S} / \mathrm{N})$ ratio to quantify the variation in data. There are three categories of $\mathrm{S} / \mathrm{N}$ ratios depending on the response characteristics. These are:

a) Higher is best (HB),

b) Lower is best (LB),

c) and Nominal is best (NB).

The $\mathrm{S} / \mathrm{N}$ ratios are calculated by using the following equations as:

$$
\begin{aligned}
& \text { HB: S/ N ratio }= \\
& \text { LB: S/N ratio }= \\
& -10 \log _{10}\left[\frac{1}{\mathrm{n}} \sum_{\mathrm{i}=1}^{\mathrm{n}} \mathrm{y}_{\mathrm{i}}^{-2}\left[\frac{1}{\mathrm{n}} \sum_{\mathrm{i}=1}^{\mathrm{n}} \mathrm{y}_{\mathrm{i}}^{2}\right]\right. \\
& \text { NB: S/ N ratio }=
\end{aligned}
$$


where $\mathrm{y}$ is the sample mean, $\mathrm{s}$ is the sample standard deviation of $\mathrm{n}$ observations in each trial. The selected response characteristics in this study are the material removal rate (MRR), tool wear rate (TWR) and surface roughness (SR). Material removal rate (MRR) has been considered as "higher the best". TWR and SR are "lower is better" type of quality characteristic, therefore lower values of TWR and SR are considered to be optimal. In this experiment, there are four parameters at three levels each. Total DOF for the experiment is 8 .

There are three interactions (between current and pulse on time, current and pulse off time, current and powder concentration) which are to be studied in the experiment.
The Orthogonal Array (OA) which is to be used is $\mathrm{L}_{27}$. The experiments have been conducted according to the trial conditions as specified in standard Taguchi method of $\mathrm{L}_{27}$ Orthogonal Array. After the obtaining the experimental results, analysis of the results have been carried out analytically as well as graphically. For graphical analysis of the experimental results plots, effects of all the factors upon responses are generated in MINITAB 15 software. Then, ANOVA of the experimental data has been calculated to find the contribution of each factor in each response. After studying the effect of all the factors on all the responses individually, signal to noise ratio has been calculated for each response.

Table -5: Process Parameters and Their Levels

\begin{tabular}{|l|l|l|l|l|}
\hline Levels & \multicolumn{2}{l|}{} \\
\hline Factor symbol & Process Parameter & 1 & 2 & 3 \\
\hline A & Peak current $(\mathrm{A})$ & 4 & 6 & 8 \\
\hline B & Pulse on time $(\mu \mathrm{s})$ & 10 & 50 & 100 \\
\hline C & Pulse off time $(\mu \mathrm{s})$ & 38 & 57 & 85 \\
\hline D & Powder concentration $(\mathrm{g} / \mathrm{l})$ & 2 & 4 & 6 \\
\hline
\end{tabular}

Table -6: DOF allocated to various factor combinations

\begin{tabular}{|l|l|l|}
\hline Interaction & Units & DOF \\
\hline Current (A) & $\mathrm{A}$ & 2 \\
\hline Pulse on-time (B) & $\mu \mathrm{s}$ & 2 \\
\hline Pulse off-time (C) & $\mu \mathrm{s}$ & 2 \\
\hline Powder concentration (D) & $\mathrm{g} / \mathrm{l}$ & 2 \\
\hline AXB & - & 4 \\
\hline AXC & - & 4 \\
\hline AXD & - & 4 \\
\hline Total & & 20 \\
\hline
\end{tabular}

The response variables selected in this study can be calculated by the following formula:

$$
\operatorname{MRR}\left(\mathrm{mm}^{3} / \mathrm{min}\right)=\frac{\text { Workpiece weight loss }(\mathrm{g})}{\text { Machining time }(\min ) \mathrm{X} \text { density }\left(\mathrm{g} / \mathrm{mm}^{3}\right)}
$$

$$
\operatorname{TWR}\left(\mathrm{mm}^{3} / \mathrm{min}\right)=\frac{\text { electrode weight loss }(\mathrm{g})}{\text { Machining time }(\min ) \mathrm{X} \text { density }\left(\mathrm{g} / \mathrm{mm}^{3}\right)}
$$

Also, $\mathrm{h}(\mathrm{x})$ is the value of roughness profile, $\mathrm{L}$ is evaluation length and $\mathrm{Ra}$ is arithmetic average roughness.

$$
\operatorname{SR}\left(\mathrm{R}_{a}\right)=\frac{1}{L} \int_{0}^{L}|h(\mathrm{x}) \mathrm{dx}|
$$

The workpiece and electrode has been weighed before and after each experiment using an electric balance HL 200 (Analytical Weighing Balance Machine, Electronica India). It has a capacity of $200 \mathrm{~g}$ and gives up to value of 4-digits after decimal.
Surface roughness tests have been conducted on all the samples, produced after each of the 27 trials. Inspection has been performed by using the surface roughness tester made by Mitutoyo Company; model SJ-201, Germany.

\subsection{Results and Analysis}

\subsubsection{Effect on Material Removal Rate}

As the experimental design used is orthogonal, the effect of each process parameter at different levels can be found. A confidence interval of $95 \%$ has been used for the analysis. Using MINITAB, raw data collected from trial experiment has been converted into their respective $\mathrm{S} / \mathrm{N}$ ratio. The effect of four parameters i.e. current, pulse on time, pulse off time and powder concentration on MRR has been shown in Figure 2. It shows that rate of material removal is low for lower values of peak current. Low values of current produces a small amount of heat. Some portion of heat is absorbed by the surroundings and left heat is utilized to melt and vaporize work material. As the current is increased, more powerful spark with higher energy is produced. More heat is generated and a substantial amount of heat is used to melt and vaporize the work material. This leads to increase in MRR. 
Table -7: Value of various responses and SNR for MRR

\begin{tabular}{|c|c|c|c|c|c|c|}
\hline \multirow{2}{*}{ S.No. } & \multirow{2}{*}{$\begin{array}{l}\text { Current } \\
\text { (ampere) }\end{array}$} & \multirow{2}{*}{$\begin{array}{l}\text { Pulse on } \\
\text { time }(\mu \mathrm{s})\end{array}$} & \multirow{2}{*}{$\begin{array}{l}\text { Pulse off } \\
\text { time }(\mu \mathrm{s})\end{array}$} & \multirow{2}{*}{$\begin{array}{l}\text { Powder } \\
\text { concentration }(\mathrm{g} / \mathrm{l})\end{array}$} & \multirow{2}{*}{$\begin{array}{l}\text { MRR } \\
\left(\mathrm{mm}^{3} / \mathrm{min}\right)\end{array}$} & \multirow{2}{*}{$\begin{array}{l}\text { SNR for } \\
\text { MRR }\end{array}$} \\
\hline & & & & & & \\
\hline 1 & 4 & 10 & 38 & 2 & 5.775 & 15.231 \\
\hline 2 & 4 & 10 & 57 & 4 & 3.653 & 11.25 \\
\hline 3 & 4 & 10 & 85 & 6 & 2.751 & 8.789 \\
\hline 4 & 4 & 50 & 38 & 4 & 3.653 & 11.25 \\
\hline 5 & 4 & 50 & 57 & 6 & 1.551 & 3.81 \\
\hline 6 & 4 & 50 & 85 & 2 & 3.851 & 11.71 \\
\hline 7 & 4 & 100 & 38 & 6 & 2.119 & 6.52 \\
\hline 8 & 4 & 100 & 57 & 2 & 3.751 & 11.48 \\
\hline 9 & 4 & 100 & 85 & 4 & 3.229 & 10.18 \\
\hline 10 & 6 & 10 & 38 & 2 & 6.123 & 15.74 \\
\hline 11 & 6 & 10 & 57 & 4 & 5.329 & 14.53 \\
\hline 12 & 6 & 10 & 85 & 6 & 3.211 & 10.13 \\
\hline 13 & 6 & 50 & 38 & 4 & 6.831 & 16.68 \\
\hline 14 & 6 & 50 & 57 & 6 & 6.811 & 16.66 \\
\hline 15 & 6 & 50 & 85 & 2 & 6.85 & 16.71 \\
\hline 16 & 6 & 100 & 38 & 6 & 7.898 & 17.95 \\
\hline 17 & 6 & 100 & 57 & 2 & 6.557 & 16.33 \\
\hline 18 & 6 & 100 & 85 & 4 & 6.133 & 15.75 \\
\hline 19 & 8 & 10 & 38 & 2 & 5.841 & 15.33 \\
\hline 20 & 8 & 10 & 57 & 4 & 3.322 & 10.43 \\
\hline 21 & 8 & 10 & 85 & 6 & 3.021 & 9.6 \\
\hline 22 & 8 & 50 & 38 & 4 & 8.522 & 18.61 \\
\hline 23 & 8 & 50 & 57 & 6 & 7.11 & 17.03 \\
\hline 24 & 8 & 50 & 85 & 2 & 8.911 & 18.99 \\
\hline 25 & 8 & 100 & 38 & 6 & 9.631 & 19.67 \\
\hline 26 & 8 & 100 & 57 & 2 & 8.758 & 18.85 \\
\hline 27 & 8 & 100 & 85 & 4 & 10.898 & 20.74 \\
\hline
\end{tabular}

This result is in line with findings of Kansal et. al and Syed et. al. An increase in pulse on time (pulse duration) leads to an increase in duration of sparking and decrease in expansion of plasma channel. It can be seen in Figure 2 MRR increases with an increase in pulse on time. With an increase in pulse on time, the sparking duration is increased. This results in increase in MRR. An increase in pulse off time (pulse interval) first decreases and then increases the MRR. MRR decreases due to the increase in the sparking time. Also, there is a considerable decrease in MRR with an increase of concentration of chromium powder. The reason for the decrease of MRR is mainly attributed to the lower breakdown strength of the dielectric fluid when conductive powder particles are added to it, due to which, the spark gap distance is increased. It is expected that the increase in gap voltage causes inadequate cooling of work material due to unfavorable concentrated discharging.

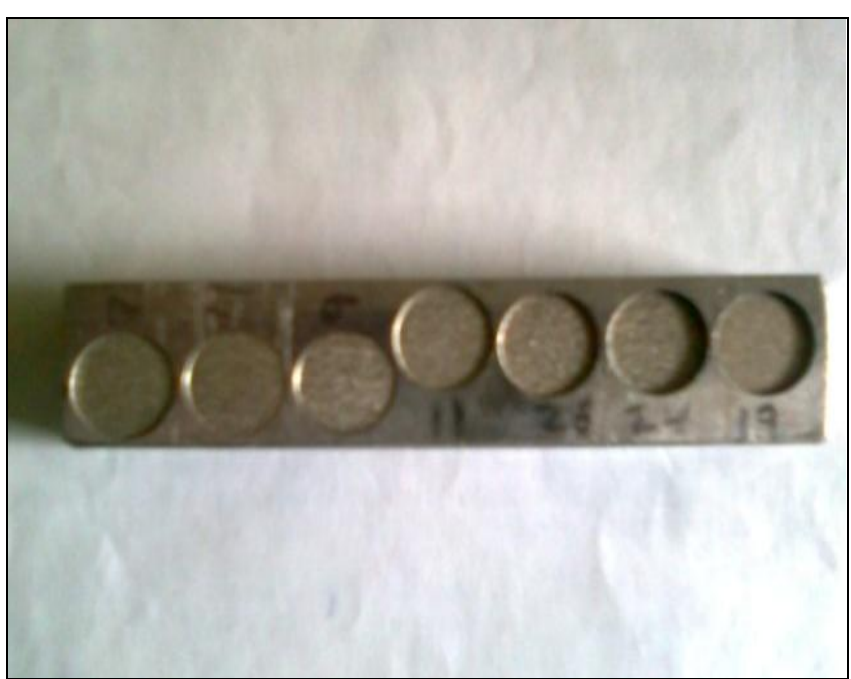

Fig -1: Specimen after machining at PMEDM 


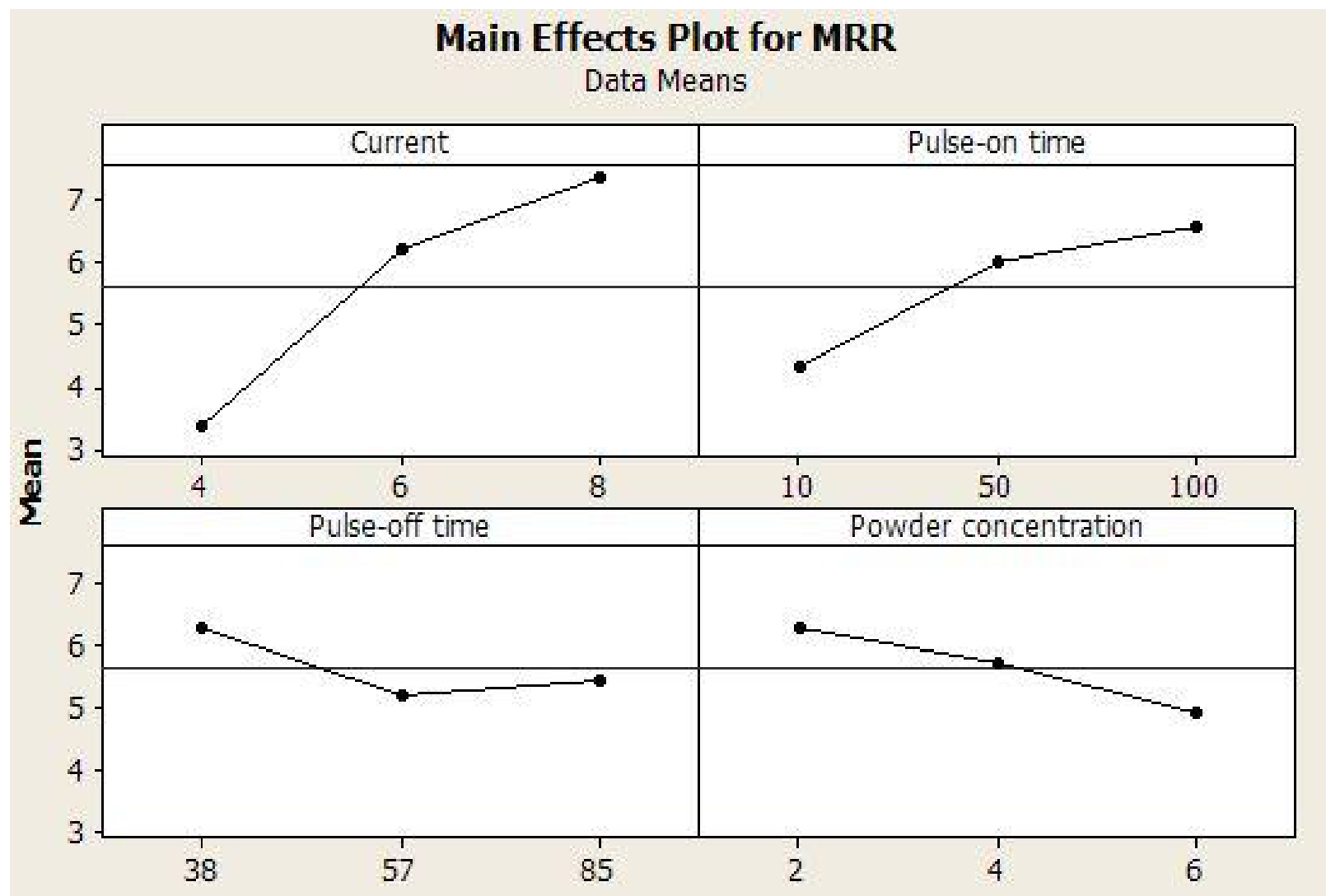

Fig -2: Effect of various factors on the MRR.

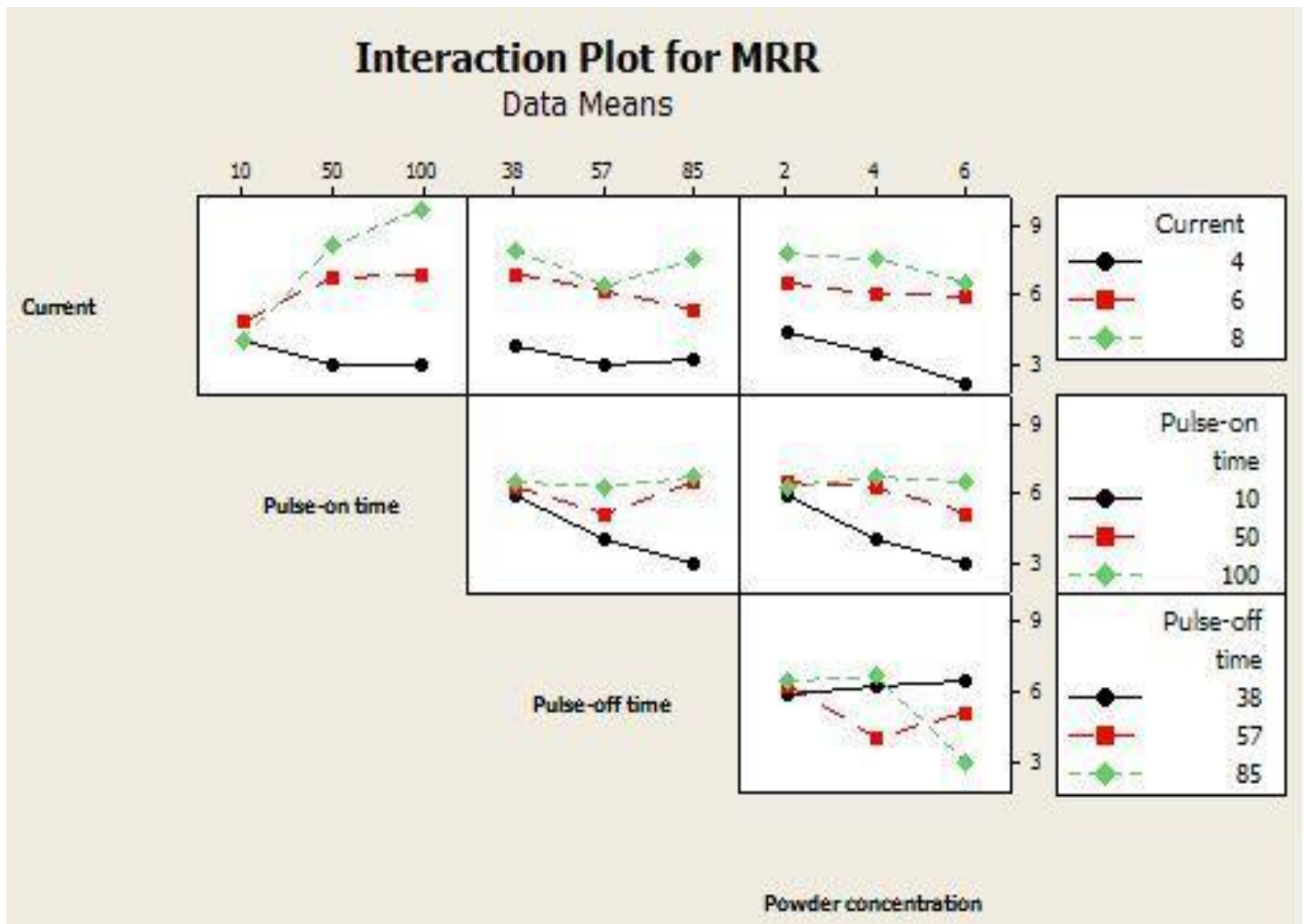

Fig -3: Interaction plot for MRR. 
Figure 3 shows the interactive effect of four parameters on MRR. These graphs indicate that maximum MRR is at the highest combination level of current and pulse off time. Same results are then followed by current and pulse on time. Hence, current of 8 amperes and pulse on time at $100 \mu \mathrm{s}$ gives the higher MRR.

To determine which parameters significantly affect the process performance, analysis of variance (ANOVA) has been performed. The ANOVA results for mean values at $95 \%$ confidence interval are shown in Table 8 . It can be seen that the current is found to be the most significant factor and its contribution to MRR is highest followed by pulse on time and powder concentration respectively. The interaction between current and pulse on time is found to be most significant. It can also be observed that parameters A, $B$ and $D$ affect the MRR significantly. The effect of parameter $\mathrm{C}$ is insignificant. The $\mathrm{S} / \mathrm{N}$ ratio consolidates several repetitions into one value and is an indication of the amount of variation present. The $\mathrm{S} / \mathrm{N}$ ratio has been calculated to identify the major contributing factors and interactions that cause variation in the MRR. Table 9 shows the ANOVA results for $\mathrm{S} / \mathrm{N}$ ratio of $\mathrm{MRR}$ at $95 \%$ confidence interval. Results show that current, powder concentration and interaction between current and pulse on time are the significant factors which affect the $\mathrm{S} / \mathrm{N}$ ratio of MRR. Table 10 shows the mean value of process parameters for MRR. The individual effect of these three parameters on the average value of MRR and $\mathrm{S} / \mathrm{N}$ ratio is shown in Table 11. Table 11 shows the average values of MRR and the respective $\mathrm{S} / \mathrm{N}$ ratios for each parameter at levels 1, 2 and 3. MRR is "higher is better" type of quality characteristic, therefore, greater values of MRR are considered to be optimal.

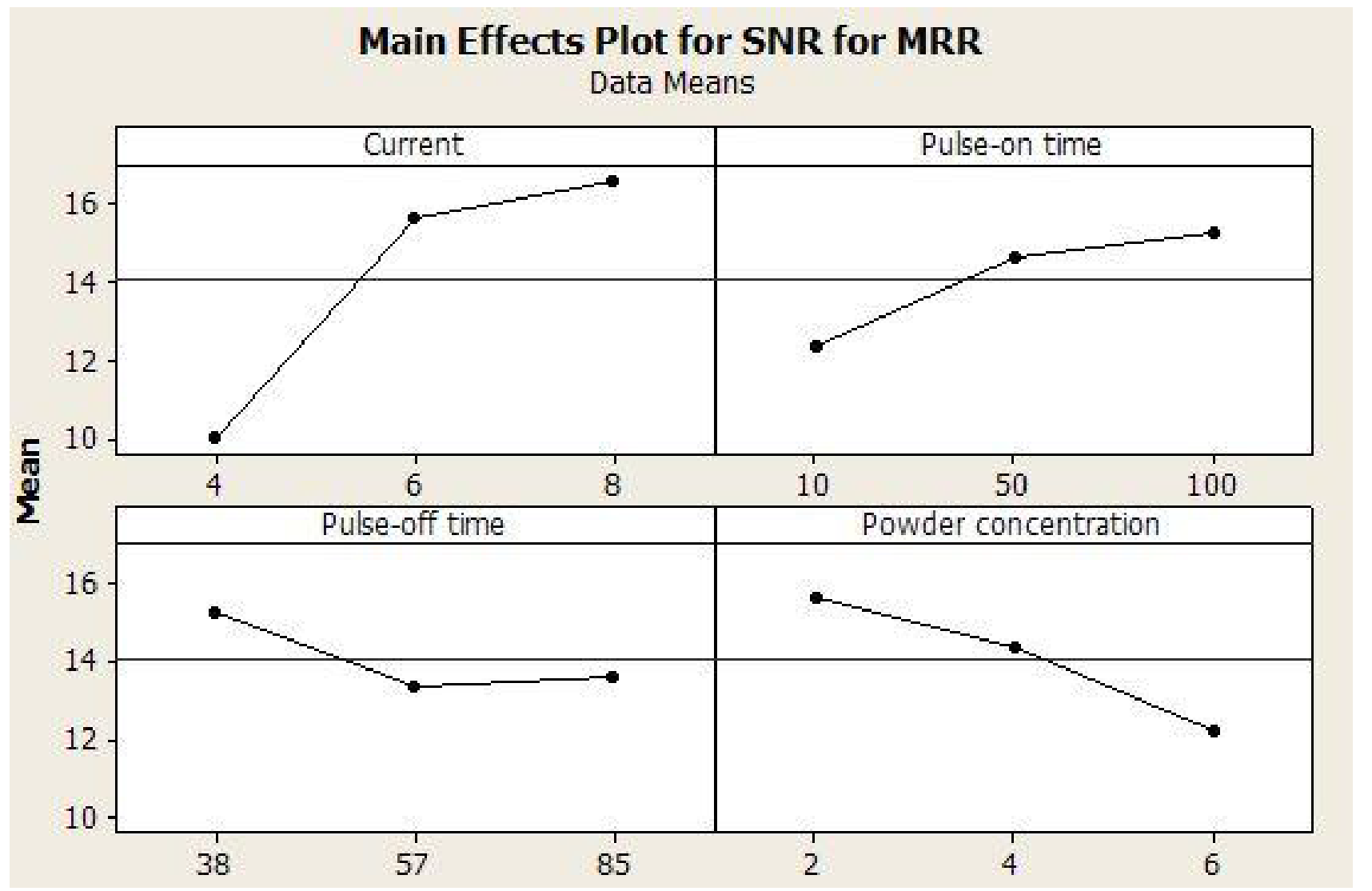

Fig -4: Main effects plot for MRR of S/N ratio.

From Figure 4 and the ANOVA results for mean and S/N data of MRR, it can be deduced that A3, B3 and D1 produce optimum MRR when machined using chromium powder mixed EDM. The process parameters and their selected optimum levels are given in Table 12. The mean value of MRR is $5.631 \mathrm{~mm}^{3} / \mathrm{min}$.

Table -8: ANOVA table for Material Removal Rate.

\begin{tabular}{|l|l|l|l|l|l|l|l|l|}
\hline Source & SS & DOF & Variance & F test & F critical & SS $^{\prime}$ & C\% & \\
\hline $\begin{array}{l}\text { Current } \\
\text { (A) }\end{array}$ & 74.9739 & 2 & 37.4895 & 51.285 & 5.14 & 72.968 & 45.22 & S \\
\hline $\begin{array}{l}\text { Pulse on } \\
\text { time (B) }\end{array}$ & 24.0259 & 2 & 12.013 & 16.433 & 5.14 & 22.02 & 13.64 & S \\
\hline
\end{tabular}




\begin{tabular}{|c|c|c|c|c|c|c|c|c|}
\hline $\begin{array}{l}\text { Pulse off } \\
\text { time }(\mathrm{C})\end{array}$ & 5.6332 & 2 & 2.816 & 3.853 & 5.14 & & & NS \\
\hline $\begin{array}{l}\text { Powder } \\
\text { Conc. } \\
\text { (D) } \\
\end{array}$ & 8.5513 & 2 & 4.275 & 5.848 & 5.14 & 6.545 & 4.056 & $\mathrm{~S}$ \\
\hline $\mathrm{A} \times \mathrm{B}$ & 37.7633 & 4 & 9.441 & 12.914 & 4.53 & 33.751 & 20.91 & $S$ \\
\hline $\mathrm{A} \times \mathrm{C}$ & 3.3357 & 4 & 0.834 & 1.14 & 4.53 & & & $\mathrm{NS}$ \\
\hline$A \times D$ & 2.6895 & 4 & 0.6723 & 0.92 & 4.53 & & & NS \\
\hline Error & 4.3879 & 6 & 0.731 & & & & & \\
\hline Total & 161.36 & 26 & & & & & & \\
\hline e-pooled & 16.046 & 24 & 1.00289 & & & & & \\
\hline
\end{tabular}

Table -9: ANOVA table for S/N ratio of Material Removal Rate.

\begin{tabular}{|c|c|c|c|c|c|c|c|c|}
\hline Source & SS & DOF & Variance & F test & F critical & $\mathrm{SS}^{\prime}$ & $\mathrm{C} \%$ & \\
\hline $\begin{array}{l}\text { Current } \\
\text { (A) }\end{array}$ & 225.464 & 2 & 112.732 & 47.2 & 10.9 & 209.51 & 43.29 & $S$ \\
\hline $\begin{array}{l}\text { Pulse on } \\
\text { time (B) }\end{array}$ & 42.677 & 2 & 21.3385 & 8.93 & 10.9 & & & NS \\
\hline $\begin{array}{l}\text { Pulse } \\
\text { off time } \\
\text { (C) }\end{array}$ & 18.064 & 2 & 9.032 & 3.78 & 10.9 & & & NS \\
\hline $\begin{array}{l}\text { Powder } \\
\text { Conc. } \\
\text { (D) }\end{array}$ & 51.988 & 2 & 25.994 & 10.92 & 10.9 & 36.034 & 7.45 & S \\
\hline $\mathrm{A} \times \mathrm{B}$ & 98.917 & 4 & 24.729 & 10.39 & 9.15 & 67.009 & 13.84 & $\mathrm{~S}$ \\
\hline $\mathrm{A} \times \mathrm{C}$ & 8.375 & 4 & 2.093 & 0.876 & 9.15 & & & NS \\
\hline$A \times D$ & 24.1 & 4 & 6.025 & 2.523 & 9.15 & & & NS \\
\hline Error & 14.33 & 6 & 2.38 & & & & & \\
\hline Total & 483.915 & 26 & 18.61 & & & & & \\
\hline $\begin{array}{l}\text { e- } \\
\text { pooled }\end{array}$ & 159.534 & 20 & 7.977 & & & & & \\
\hline
\end{tabular}

Table -10: Mean values of process parameters for MRR

\begin{tabular}{|l|l|l|l|}
\hline \multirow{2}{*}{ Process Parameters } & Levels & Mean MRR (mm 3 /min.) & S/N Ratio \\
\hline \multirow{4}{*}{ Peak current (A) } & 1 & 3.37 & 10.024 \\
\cline { 2 - 4 } & 2 & 6.19 & 15.608 \\
\cline { 2 - 4 } & 3 & 7.33 & 16.583 \\
\hline \multirow{3}{*}{ Pulse on time (B) } & 1 & 4.336 & 12.336 \\
\cline { 2 - 4 } & 2 & 6.01 & 14.605 \\
\cline { 2 - 4 } & 3 & 6.55 & 15.274 \\
\hline \multirow{3}{*}{ Powder concentration (D) } & 1 & 6.268 & 15.596 \\
\cline { 2 - 4 } & 2 & 5.73 & 14.38 \\
\cline { 2 - 4 } & 3 & 4.9 & 12.239 \\
\hline
\end{tabular}


Table -11: Optimum levels of process parameters.

\begin{tabular}{|l|l|l|}
\hline Process Parameters & Parameter Designation & Optimum Level \\
\hline Peak current $(\mathrm{A})$ & $\mathrm{A}_{3}$ & 8 \\
\hline Pulse on time $(\mu \mathrm{s})$ & $\mathrm{B}_{3}$ & 100 \\
\hline Powder concentration $(\mathrm{g} / \mathrm{l})$ & $\mathrm{D}_{1}$ & 2 \\
\hline
\end{tabular}

The theoretical optimal value for response characteristics is given as follows:

$(\mathrm{MRR})_{\mathrm{opt}}=$ Average performance + Contribution of significant factors at optimum levels

$(\mathrm{MRR})_{\mathrm{opt}}=\overline{\mathrm{T}}+\left(\mathrm{A}_{3}-\overline{\mathrm{T}}\right)+\left(\mathrm{B}_{3}-\overline{\mathrm{T}}\right)+\left(\mathrm{D}_{1}-\overline{\mathrm{T}}\right)$

$=5.631+(7.33-5.631)+(6.55-5.631)+(6.268-5.631)=8.886 \mathrm{~mm}^{3} / \mathrm{min}$.

\subsubsection{Effect on Tool Wear Rate}

Figure 5 shows the effect of various factors upon the tool wear rate (TWR). TWR increases with peak current. The faster sparking takes place will cause faster erosion from the electrode surface. It is also observed that TWR increases slightly with the increase in pulse-on time. Also, TWR slightly increases with the increase of pulse-off time. TWR slightly decreases with the increase of concentration of powder. It is due to the reason that initially the availability of energy per spark during discharging is more which then lowers down with the addition of impurities in the dielectric due to the increase in the spark gap.

Figure 6 gives the interactive effect of various factors upon the TWR. It shows that for current and pulse-on time combination, TWR shows an increase with all the three levels of current with increase in the pulse-on time value.

Also, graphically, maximum effect for the minimum tool wear rate is achieved by current and powder concentration combination.

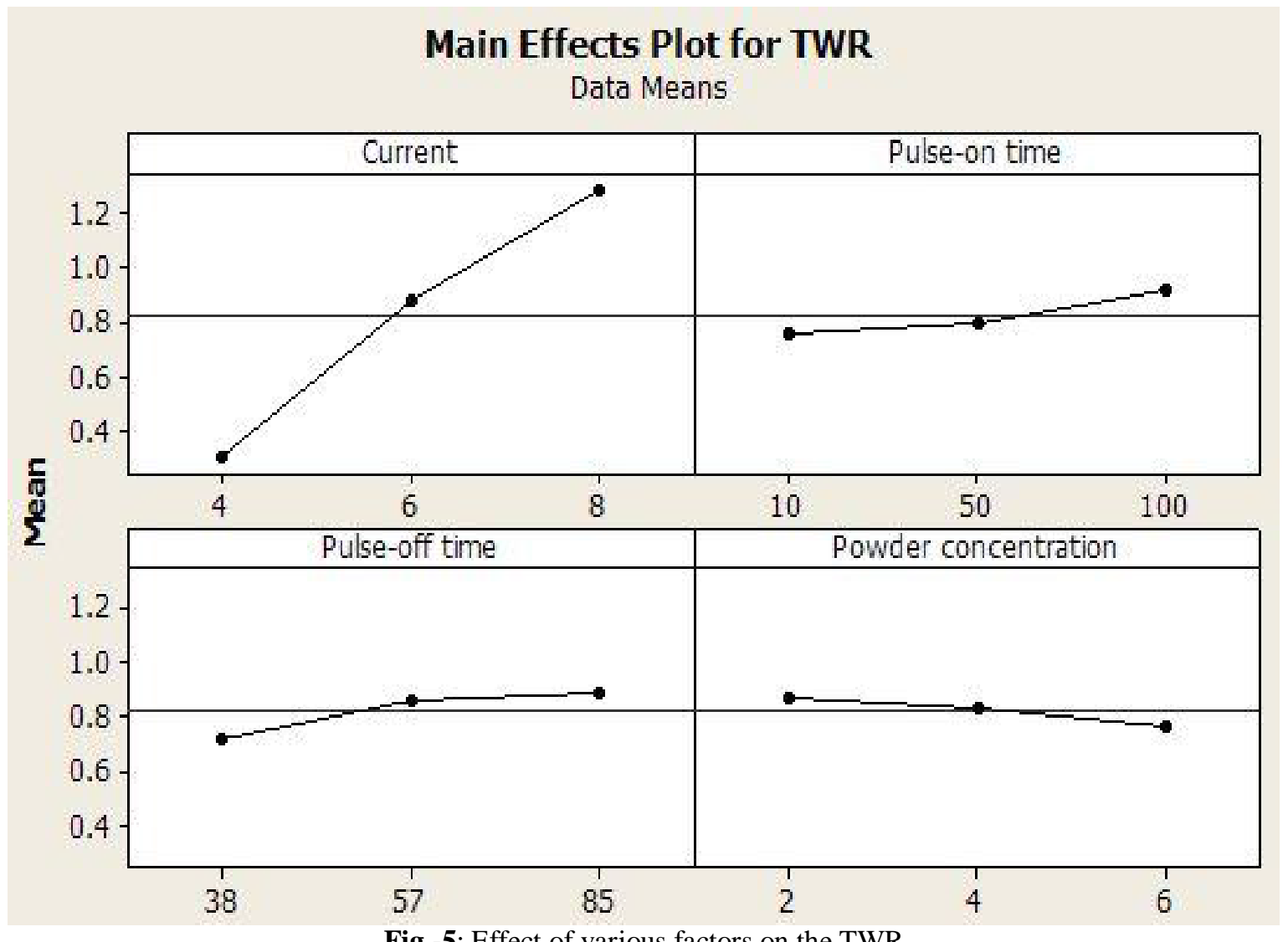

Fig -5: Effect of various factors on the TWR 


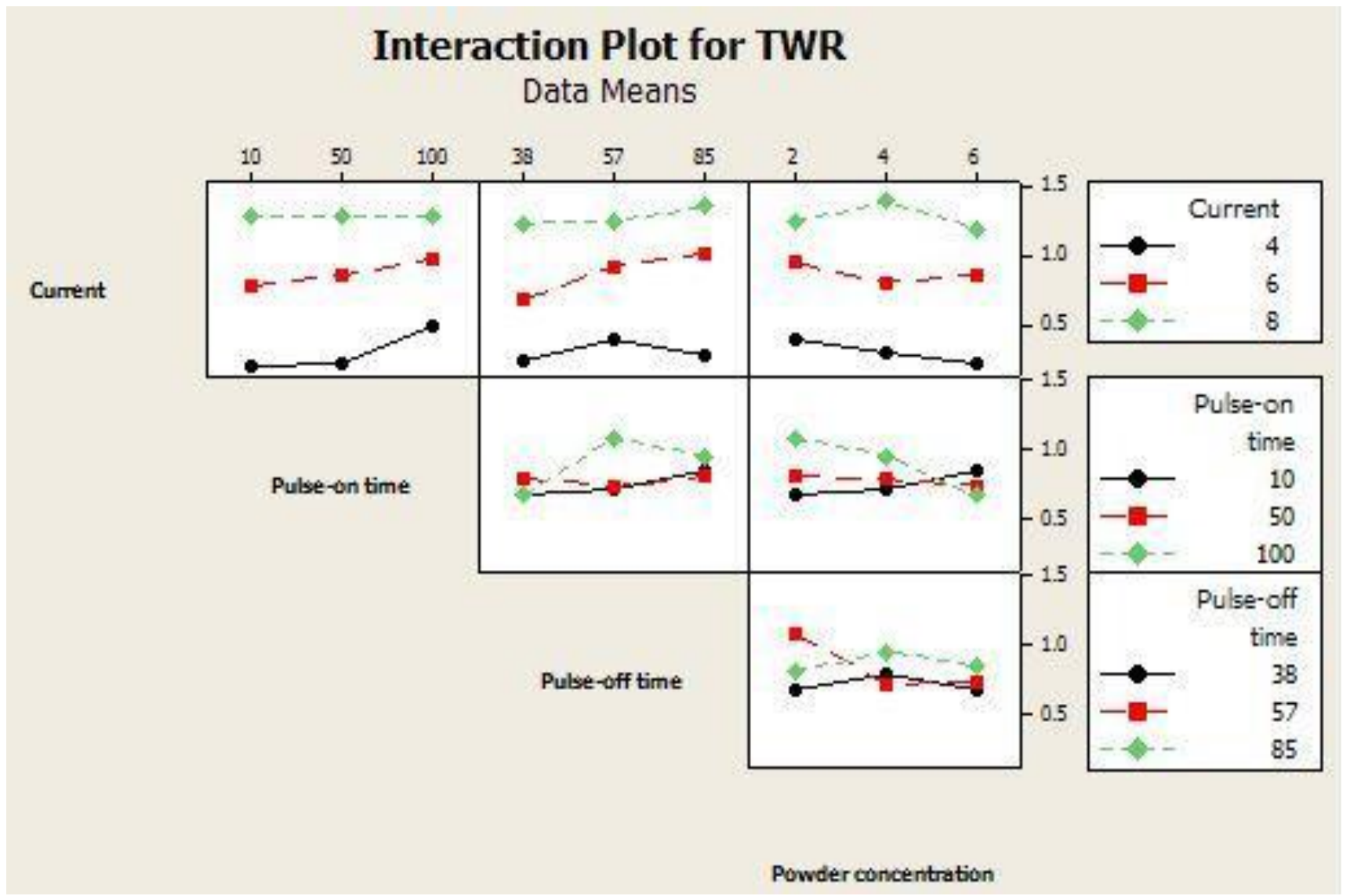

Fig -6: Interaction plot for TWR

Table 12 shows the ANOVA results for TWR at 95\% confidence interval. MINITAB15 software is used for developing the table.

Table -12: ANOVA table of Tool Wear Rate

\begin{tabular}{|c|c|c|c|c|c|c|c|c|}
\hline Source & SS & DOF & Variance & F test & F critical & $\mathrm{SS}^{\prime}$ & $\mathrm{C} \%$ & \\
\hline $\begin{array}{l}\text { Current } \\
\text { (A) }\end{array}$ & 4.345 & 2 & 2.173 & 64.92 & 5.14 & 4.277 & 82.969 & $S$ \\
\hline $\begin{array}{l}\text { Pulse-on } \\
\text { time (B) }\end{array}$ & 0.127 & 2 & 0.0635 & 1.898 & 5.14 & & & NS \\
\hline $\begin{array}{l}\text { Pulse-off } \\
\text { time }(\mathrm{C})\end{array}$ & 0.139 & 2 & 0.0695 & 2.079 & 5.14 & & & NS \\
\hline $\begin{array}{l}\text { Powder } \\
\text { Conc. (D) }\end{array}$ & 0.05 & 2 & 0.025 & 0.749 & 5.14 & & & NS \\
\hline $\mathrm{A} \times \mathrm{B}$ & 0.08 & 4 & 0.0212 & 0.633 & 4.53 & & & NS \\
\hline $\mathrm{A} \times \mathrm{C}$ & 0.11 & 4 & 0.0275 & 0.823 & 4.53 & & & NS \\
\hline$A \times D$ & 0.098 & 4 & 0.0245 & 0.733 & 4.53 & & & $\mathrm{NS}$ \\
\hline error & 0.2 & 6 & 0.03347 & & & & & \\
\hline Total & 5.155 & 26 & & & & & & \\
\hline e-pooled & 0.81 & 24 & 0.03377 & & & & & \\
\hline
\end{tabular}

From the results of the ANOVA table, it is clear that except current all the other parameters (pulse on time, pulse off time and powder concentration) and their interactions factors are found to be insignificant. They have no effect on the tool wear rate individually. Current is found to be the most significant factor and its contribution to TWR is $82.969 \%$. Hence, except current, no parameter has significant effect on TWR. The individual effect of this parameter on the average value of TWR and S/N ratio at levels 1, 2, 3 is shown in Table 13: 
Table -13: Mean values of process parameters for TWR

\begin{tabular}{|l|l|l|l|}
\hline Process Parameters & Levels & Mean TWR $\left(\mathrm{mm}^{3} / \mathrm{min}.\right)$ & S/N Ratio \\
\hline \multirow{3}{*}{ Peak current (A) } & 1 & 0.3055 & 11.488 \\
\cline { 2 - 5 } & 2 & 0.8751 & 12.198 \\
\cline { 2 - 4 } & 3 & 1.283 & -19.088 \\
\hline
\end{tabular}

TWR is "lower is better" type of quality characteristic, therefore lower values of TWR are considered to be optimal.

Table -14: Optimum Levels of Process Parameters

\begin{tabular}{|l|l|l|}
\hline Process Parameters & Parameter Designation & Optimum Level \\
\hline Peak current $(\mu \mathrm{s})$ & $\mathrm{A}_{1}$ & 4 \\
\hline
\end{tabular}

The mean value of TWR is $0.8212 \mathrm{~mm}^{3} / \mathrm{min}$. The formula for calculating the theoretical optimal value is given as under:

$$
\begin{aligned}
& (\mathrm{TWR})_{\mathrm{opt}}=\bar{T}+\left(\mathrm{A}_{1}-\bar{T}\right) \\
& =0.8212+(0.305-0.8212) \\
& =0.305 \mathrm{~mm}^{3} / \mathrm{min} .
\end{aligned}
$$

\subsubsection{Effect on Surface Roughness}

Figure 7 shows the effect of various factors i.e. current, pulse on-time, pulse off-time and powder concentration upon the roughness of the surface. It can be observed that surface roughness of the surface initially increases with increase in the current, pulse on-time and pulse off-time. This is because of the reason that more powerful sparking at higher currents produces more pressure energy that hits the work piece surface thereby producing deeper and wider craters. But, further increase in current and pulse-on time continuously reduces the surface roughness.

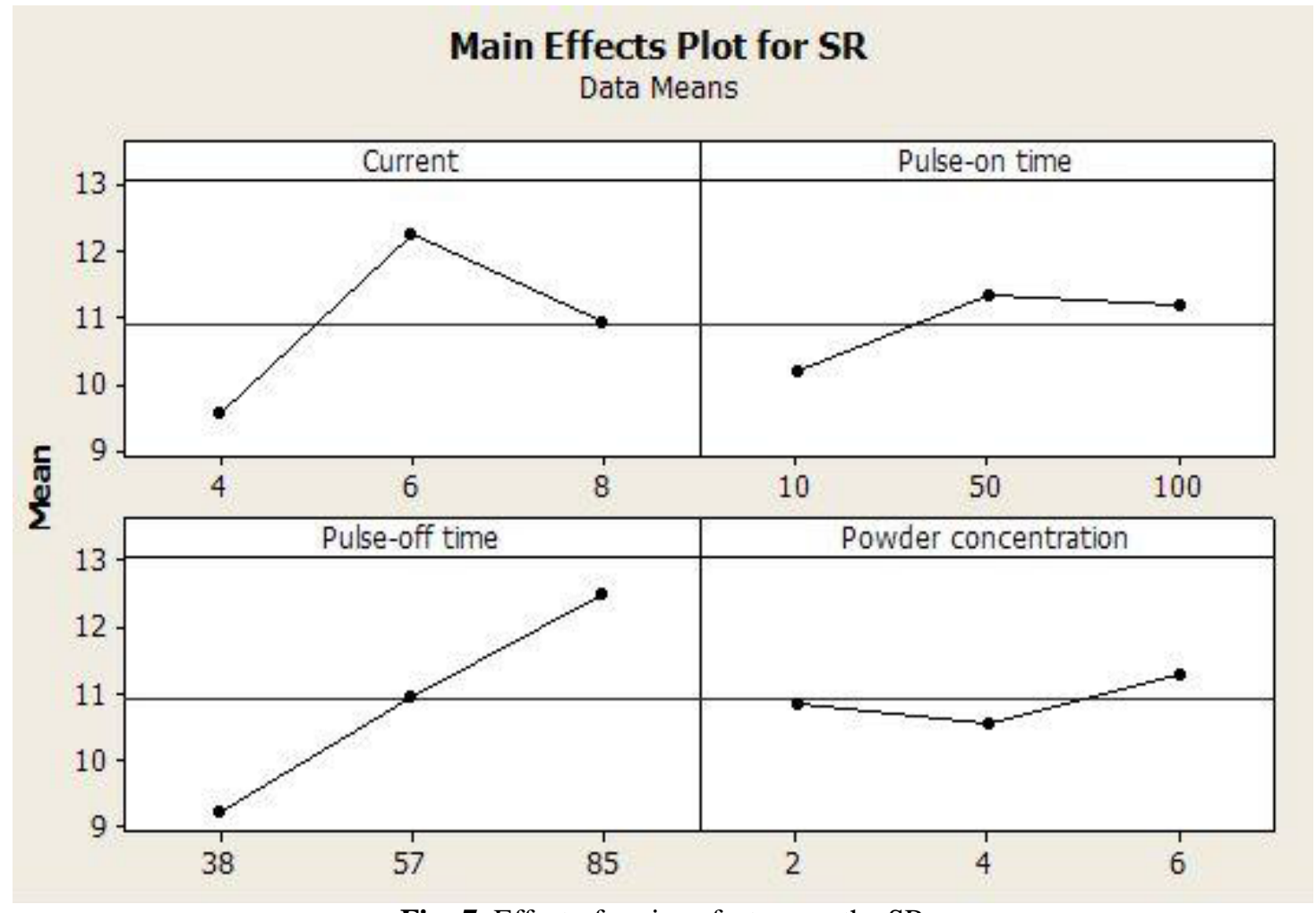

Fig -7: Effect of various factors on the SR

Also, SR increases with increase in pulse-off time. Surface roughness initially decreases with powder concentration but slightly increases at higher level. 


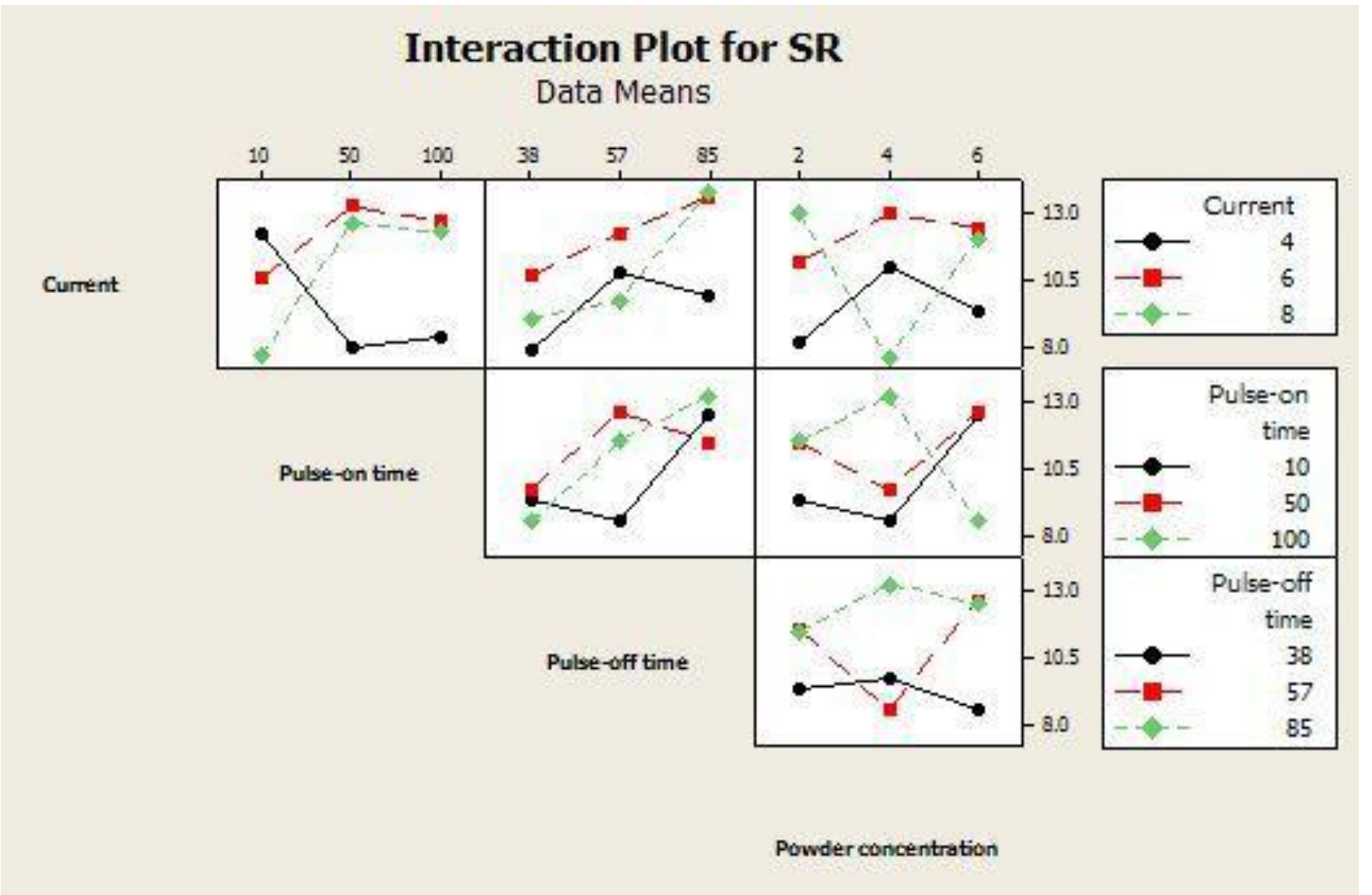

Fig -8: Interaction plot for Surface Roughness

Figure 8 shows the interactive effect of all the factors i.e. input parameters (current, pulse on-time, pulse off-time and powder concentration) upon the response i.e. surface roughness. It can be inferred that surface roughness increases with increase in current, pulse on-time and pulse-off time. The effect of combination of current and pulse off-time gives the maximum surface roughness.

Table 15 shows the ANOVA results for surface roughness at $95 \%$ confidence interval. From the results of the ANOVA table, it is clear that except pulse-off time all the other parameters (current, pulse-on time and powder concentration) and interaction factors have no effect on the surface roughness individually and are found to be insignificant. Pulse-off time is found to be the most significant factor and its contribution to SR is $12.03 \%$.

Table -15: ANOVA table of Surface Roughness

\begin{tabular}{|l|l|l|l|l|l|l|l|l|}
\hline Source & SS & DOF & Variance & F test & F critical & SS $^{\prime}$ & C\% & \\
\hline Current (A) & 28.7923 & 2 & 14.396 & 2.887 & 5.14 & & & NS \\
\hline $\begin{array}{l}\text { Pulse-on } \\
\text { time (B) }\end{array}$ & 5.5876 & 2 & 2.794 & 0.56 & 5.14 & & & NS \\
\hline $\begin{array}{l}\text { Pulse-off } \\
\text { time (C) }\end{array}$ & 53.6669 & 2 & 26.833 & 5.381 & 5.14 & 34.3469 & 12.03 & S \\
\hline $\begin{array}{l}\text { Powder } \\
\text { Conc. (D) }\end{array}$ & 3.9577 & 2 & 1.978 & 0.3967 & 5.14 & & & NS \\
\hline A $\times$ B & 83.9832 & 4 & 20.996 & 4.21 & 4.53 & & & NS \\
\hline A $\times$ C & 18.6163 & 4 & 4.654 & 0.933 & 4.53 & & & NS \\
\hline A $\times$ D & 60.9859 & 4 & 15.246 & 3.057 & 4.53 & & & NS \\
\hline error & 29.9218 & 6 & 4.986 & & & & & \\
\hline Total & 285.5117 & 26 & 10.98 & & & & & \\
\hline e-pooled & 231.8448 & 24 & 9.66 & & & & & \\
\hline
\end{tabular}




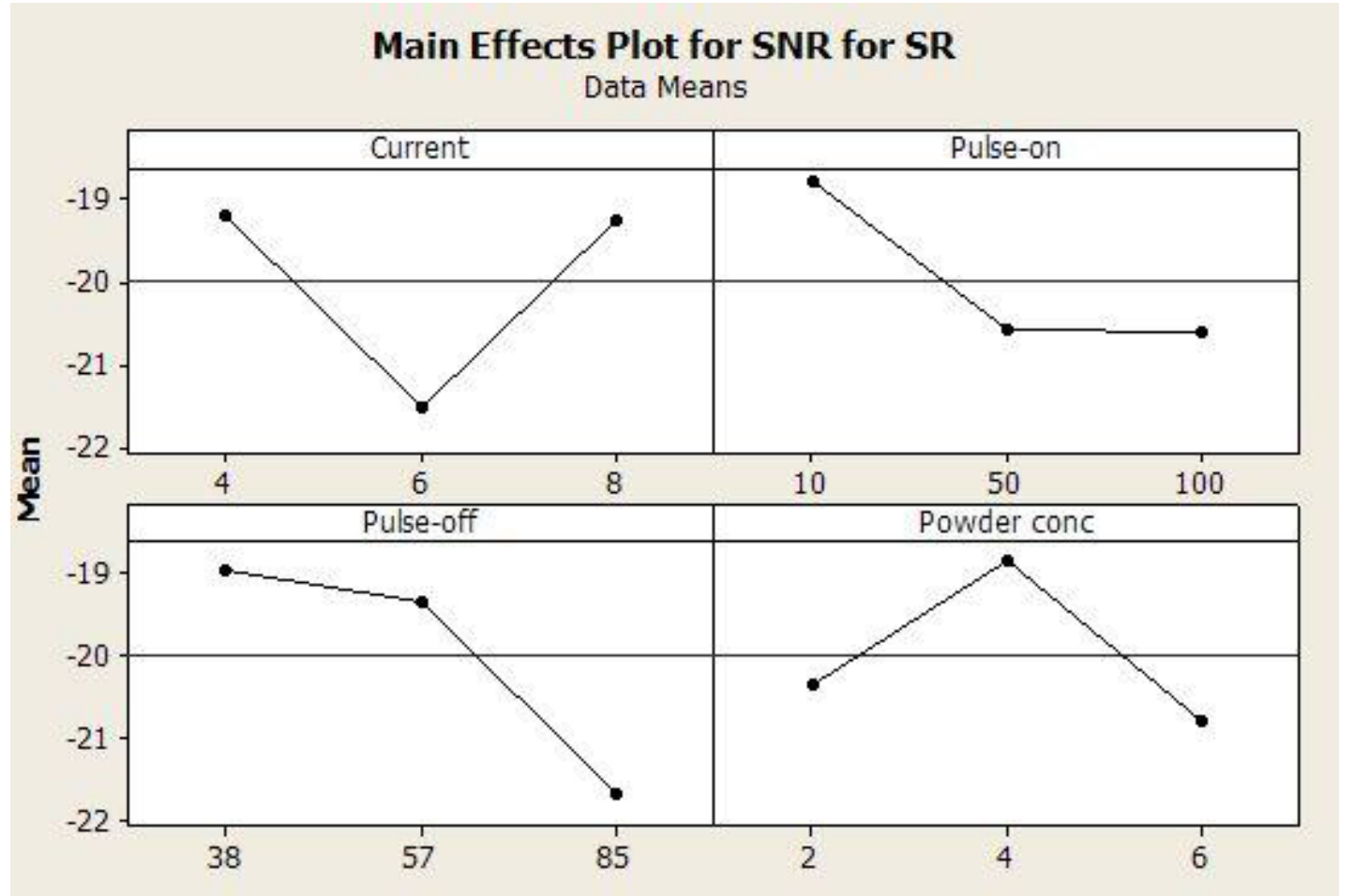

Fig -9: Main effects plot for S/N ratio of Surface Roughness

As one process parameter is significant, the individual effect of this parameter on the average value of SR and S/N ratio at levels $1,2,3$ is shown in Table 16 :

Table -16: Mean values of process parameters for SR

\begin{tabular}{|l|l|l|l|}
\hline \multirow{2}{*}{ Process Parameters } & Levels & Mean SR $(\mu)$ & S/N Ratio \\
\hline \multirow{3}{*}{ Pulse-off time (C) } & 1 & 9.065 & -18.961 \\
\cline { 2 - 4 } & 2 & 10.975 & -19.349 \\
\cline { 2 - 4 } & 3 & 12.512 & -21.684 \\
\hline
\end{tabular}

SR is "lower is better" type of quality characteristic, therefore lower values of SR are considered to be optimal.

Table -17: Optimum Levels of Process Parameters

\begin{tabular}{|l|l|l|}
\hline Process Parameters & Parameter Designation & Optimum Level \\
\hline Pulse-off time $(\mu \mathrm{s})$ & $\mathrm{C}_{1}$ & 38 \\
\hline
\end{tabular}

The mean value of SR is $10.85 \mu \mathrm{m}$. The formula for calculating the theoretical optimal value is given as under:

$$
\begin{aligned}
& (\mathrm{SR})_{\mathrm{opt}}=\bar{T}+\left(\mathrm{C}_{1}-\bar{T}\right) \\
= & 10.85+(9.065-10.85) \\
= & 9.065 \mu \mathrm{m}
\end{aligned}
$$

The $\mathrm{S} / \mathrm{N}$ ratio consolidates several repetitions into one value and is an indication of the amount of variation present. The $\mathrm{S} / \mathrm{N}$ ratio has been calculated to identify the major contributing factors and interactions that cause variation in the SR. SR is "Lower is better" type response which is given by:

$$
\mathrm{LB}: \mathrm{S} / \mathrm{N} \text { ratio }=-10 \log _{10}\left[\frac{1}{n} \sum_{i=1}^{n} Y_{i}^{2}\right]
$$

Table 18 shows the ANOVA results for $\mathrm{S} / \mathrm{N}$ ratio of $\mathrm{SR}$ at $95 \%$ confidence interval. Results show that no parameter is significant which affects the $\mathrm{S} / \mathrm{N}$ ratio of surface roughness. 
Table -17: ANOVA for S/N ratio of Surface Roughness

\begin{tabular}{|l|l|l|l|l|l|l|}
\hline Source & SS & DOF & Variance & F test & F critical & $\begin{array}{l}\text { Whether F test } \\
>\text { F critical }\end{array}$ \\
\hline Current (A) & 31.432 & 2 & 15.716 & 0.987 & 10.9 & NS \\
\hline $\begin{array}{l}\text { Pulse-on time } \\
\text { (B) }\end{array}$ & 19.383 & 2 & 9.691 & 0.6 & 10.9 & NS \\
\hline $\begin{array}{l}\text { Pulse-off time } \\
(\mathrm{C})\end{array}$ & 39.046 & 2 & 19.523 & 1.226 & 10.9 & NS \\
\hline $\begin{array}{l}\text { Powder Conc. } \\
(\mathrm{D})\end{array}$ & 18.526 & 2 & 9.263 & 0.58 & 10.9 & NS \\
\hline A $\times$ B & 126.254 & 4 & 31.563 & 1.982 & 9.15 & NS \\
\hline A C & 57.902 & 4 & 14.475 & 0.909 & 9.15 & NS \\
\hline AxD & 112.011 & 4 & 28.002 & 1.759 & 9.15 & NS \\
\hline error & 95.505 & 6 & 15.917 & & & \\
\hline Total & 500.059 & 26 & 19.233 & & & \\
\hline e-pooled & 500.059 & 26 & 19.233 & & & \\
\hline
\end{tabular}

\section{CONCLUSION}

Based on the experiments performed on the experimental setup for the PMEDM process, following conclusions can be drawn.

1. MRR is mainly affected by current, pulse-on time and powder concentration. With the increase in current and pulse-on time, MRR increases. But it is also observed that with the increased concentration of chromium powder, MRR tends to decrease.

2. TWR is mainly affected by current. With the increase in current, TWR increases. Also, TWR tends to decrease with the increase in chromium powder concentration.

3. Current is the most dominant factor affecting both MRR and TWR. Both the performance data show an increasing pattern with increase in current for any other parameter.

4. Surface roughness is mainly affected by the pulse-off time as per the main effects plot for SR. Surface Roughness is higher with the increase in pulse-off time.

For further future experimental work, researchers can study the effect of flushing on MRR, TWR and SR. In this experiment, polarity has been kept constant. Polarity can also be varied and its effect should be studied. The effect of other types of dielectric powders such as titanium, vanadium can be studied. Effect of different particle size and concentration of powder can be experimented. Also, the debris which is left in the dielectric can be collected and analyzed to see the changes in metallurgy and properties.

\section{ACKNOWLEDGEMENTS}

The authors would like to thank the faculty, staff and fellow students of Dr. B. R. Ambedkar National Institute of Technology, Jalandhar for providing the necessary equipment and support for carrying out this work.

\section{REFERENCES}

[1]. M. L. Jeswani, "Effects of the addition of graphite powder to kerosene used as the dielectric fluid in electrical discharge machining," Wear, vol. 70, pp. 133-139, 1981
[2]. K. Kobayashi, T. Magara, Y. Ozaki and T. Yatomi, "The present and future developments of electrical discharge machining," Proceedings of 2nd International Conference on Die and Mould Technology, Singapore, pp. 35-47, 1992

[3]. B. H. Yan and S. L. Chen, "Effects of dielectric with suspended aluminum powder on EDM," Journal of the Chinese Society of Mechanical Engineers, vol. 14, no. 3, pp. 307-312, 1993

[4]. Y. S. Wong, L. C. Lim, I. Rahuman and W. M. Tee, "Near-mirror-finish phenomenon in EDM using powdermixed dielectric," International Journal of Advanced Manufacturing Technology, vol. 79, pp. 30-40, 1998

[5]. Y. Uno, A. Okada, Y. Hayashi and Y. Tabuchi, "Surface integrity in EDM of aluminum bronze with nickel powder mixed fluid," Journal of Japanese Society of Electrical Machining Engineers, vol. 32, no. 70, pp. 24-31, 1998

[6]. G. Singh, A. Batish, A. Bhattacharya, and V. K. Singla, "Investigations on improvement of material properties and parametric optimization of MRR, TWR, and roughness using powder mixed dielectric in EDM process," Master's Thesis, Department of mechanical engineering, Thapar University (Patiala), 2010

[7]. W. S. Zhao, Q. G. Meng, Z. L. Wang, "The application of research on PMEDM in rough machining," Journal of Materials Processing Technology, vol.129, pp. 30-33, 2002 [8]. P. Pecas and E. A. Henriques, "Influence of silicon powder mixed dielectric on conventional electrical discharge machining," International Journal of Machine Tools and Manufacture, vol. 43, pp. 1465-1471, 2003

[9]. H. K. Kansal, S. Singh and P. Kumar, "State of the art concerning powder mixed EDM," Proceedings of the International Conference on Emerging Technology, KIIT, Bhubaneswar, India, 2003

[10]. R. Rival, "EDM of Ti alloy using copper tungsten electrode with SiC powder suspension dielectric fluid," Master's thesis, Faculty of Mechanical Engineering, Universiti Teknologi, Malaysia, 2005 
[11]. H. K. Kansal, S. Singh and P. Kumar, "Parametric optimization of powder mixed electric discharge machining by response surface methodology," Journal of Material Processing Technology, vol. 169, pp. 427-436, 2005

[12]. H. K. Kansal, S. Singh and P. Kumar, "Technology and research developments in powder mixed electric discharge machining," Journal of Material Processing Technology, vol. 169, pp. 427-436, 2007

[13]. H. K. Kansal, S. Singh and P. Kumar, "Effect of silicon powder mixed EDM on machining rate of AISI D2 die steel," Journal of Material Processing Technology, vol. 9, no. 1, pp.32-41, 2007

[14]. P. Pecas and E. A. Henriques, "EDM using simple and powder mixed dielectric. The effect of the electrode area in the surface roughness and topography," Journal of Material Processing Technology, vol. 200, pp. 250-258, 2008

[15]. Shitij Sood, "Effect of powder mixed dielectric on MRR, TWR and surface properties in EDM," Master's Thesis, Department of mechanical engineering, Thapar University (Patiala), 2008

[16]. H. M. Chow, L. D. Yang, Y. F. Chen and C. T. Lin, "The use of $\mathrm{SiC}$ powder in water as dielectric for micro-slit EDM machining," Journal of Material Processing Technology, vol. 195, pp. 160-170, 2008

[17]. G. Kibria, B. R. Sarkar, B. B. Pradhan and B. Bhattacharyya, "Comparative study of different dielectrics for micro-EDM performance during micro-hole machining of titanium alloy," International Journal of Advanced Manufacturing Technology, vol. 48, no. 5-8, pp. 557-570, 2010

[18]. K. Y. Kung, J. T. Horng and K. T. Chiang, "Material removal rate and electrode wear ratio study on PMEDM of cobalt-bonded tungsten carbide," International Journal of Advanced Manufacturing Technology, vol. 40, no. 1-2, pp. 95-104, 2009

[19]. Shailesh K. Dewangan, "Experimental investigation of machining parameters for EDM using U-shaped electrode of AISI P20 tool steel," Master Thesis, Department of mechanical engineering, NIT Rourkela, India, 2010

[20]. R. K. Garg, Kuldeep Ojha and K. K. Singh, "The effect of Nickel powder suspended dielectric on EDM Performance Measures of EN-19 Steel," Journal of Engineering and Applied Sciences, vol. 6, no. 1, pp. 27-37, 2011

[21]. K. Furutani, A. Saneto, H. Takezawa, N. Mohri and H. Miyake, "Accretion of titanium carbide by electrical discharge machining with powder suspended in working fluid," Precision Engineering, vol. 25, pp. 138-144, 2001

[22]. A. Erden and S. Bilgin, "Role of impurities in electric discharge machining". Proceedings of the 21st International Machine Tool Design and Research Conference, (IMTDRC' 80), Macmillan, London, pp. 345-350, 1980

[23]. N. Mohri, N. Saito and M. Higash, "A new process of finish machining on free surface by EDM methods." Annals of the CIRP, vol. 40, no. 1, pp 207-210, 1991

[24] H. K. Kansal, S. Singh and P. Kumar, "Performance parameters optimization of powder mixed electric mixed electric discharge machining (PMEDM) by Taguchi method," West Indian Journal of Engineering, vol. 29, no.1, 2006
[25]. Y. F. Tzeng and C. Y. Lee, "Effects of powder characteristics on electro discharge machining efficiency", International Journal of Advance Manufacturing Technology, vol. 17, pp. 586-592, 2001

[26]. J. Simao, "Work piece surface modification using electrical discharge machining", International Journal of Machine Tools Manufacturing, vol. 43, pp. 121-128, 2003.

[27]. P. Singh, A. Kumar, N. Beri and V. Kumar, "Influence of electrical parameters in powder mixed electric discharge machining (PMEDM) of Hastelloy," Journal of Engineering Research and Studies, vol. 1, no. 2, pp. 93-105, 2010

[28]. K. H. Syed and K. Palaniyandi, "Performance of electrical discharge machining using aluminium powder suspended distilled water," Turkish Journal of Engineering and Environmental Sciences, vol. 36, no.3, pp. 195-207, 2012

\section{BIOGRAPHIES}

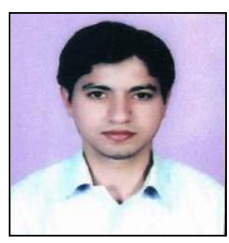

Mr. Abhishek Abrol is working as an Assistant Professor in Lovely Professional University, Phagwara. He has completed his master's from Dr. B. R. Ambedkar National Institute of Technology, Jalandhar

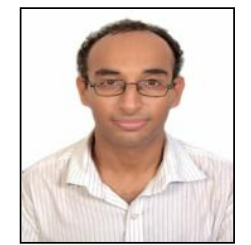

Mr. Sunil Sharma is B.Tech (Mechanical Engineering) from Punjab Technical University (PTU) and MS from Oklahoma State University with specialization in Materials and Manufacturing. Currently, he is working as an Assistant Professor in Lovely Professional University, Phagwara 